\title{
KHẢO SÁT TÌNH TRẠNG THIẾU VITAMIN D3 (25-0H) HUYẾT THANH Ở BỆNH NHÂN ĐAU CộT SỐNG THẮT LƯNG MẠN TÍNH
}

\section{TÓM TẮT}

Mục tiêu nghiên cứu: Khảo sát tình trạng thiếu Vitamin D3 $(25-\mathrm{OH})$ huyết thanh ở bệnh nhân đau cột sống thắt lưng mạn tính. Đối tượng và phương pháp nghiên cứu: Nghiên cứu mô tả cắt ngang có so sánh nội nhóm trên 82 bệnh nhân đau cột sống thắt lưng mạn tính. Kết quả: Tỷ lệ nữ/nam là 2,9/1; tuổi trung bình của nhóm bệnh nhân là $67,6 \pm 12,7$ tuổi. Nồng độ Vitamin D3 (25-OH) huyết thanh trung bình là $19,8 \pm 7,7 \mathrm{ng} / \mathrm{ml}$; trong đó tỷ lệ bệnh nhân thiếu nặng chiếm $53,7 \%$ và thiếu vừa là $39,0 \%$. Mức độ thiếu Vitamin D3 $(25-\mathrm{OH})$ huyết thanh liên quan có ý nghĩa thống kê với $p<0,05$ bao gồm: giới tính, tình trang hút thuốc lá, tình trạng uống rượu (ở nam giới), triệu chứng yễu cơ trên lâm sàng, mức độ hạn chế sinh hoạt (chỉ số Oswestry), giảm mât độ xương côtt sống ở nữ giới. Kết luận: Nghiên cứu cho thây tình trạng thiếu Vitamin D3 (25-OH) huyết thanh ở bệnh nhân đau cột sống thắt lưng mạn tính rất phổ biến và có liên quan với một số triệu chứng cơ năng của bệnh.

Tư khóa: vitamin D, đau cột sống thắt lưng

\section{SUMMARY}

\section{SURVEY FOR VITAMIN D3 (25-OH) DEFICIENCY} IN CHRONIC LOW BACK PAIN PATIENTS

Objectives: This study was to investigate vitamin D3 $(25-\mathrm{OH})$ deficiency in chronic low back pain patients. Methods: A cross-sectional study, intragroup comparison in 82 patients suffering from chronic low back pain. Results: The female/male ratio is $2,9 / 1$; The mean age of the patients group in this study was $67,6 \pm 12,7$ years. The mean serum vitamin D3 $(25-\mathrm{OH})$ concentration was $19,8 \pm 7,7 \mathrm{ng} / \mathrm{ml}$; in which the prevalence of patients with deficiency was $53,7 \%$ and vitamin D insufficiency accounted for $39,0 \%$. Some related factors having statistically significant relationship with serum vitamin D3 $(25-\mathrm{OH})$ levels including: gender, smoking and alcohol drinking in men, muscle weakness symptom clinical, degree of activity restriction (Oswestry Disability Index), reduces bone mineral density in women. Conclusion: The research found that Vitamin D3 $(25-\mathrm{OH})$ deficiency in patients with chronic low back pain was very common and was associated with some physical symptoms of the disease.

Keywords: Vitamin D, chronic low back pain

\footnotetext{
${ }^{1}$ Bệnh viện đa khoa Hưng Hà- Tp. Hưng Yên Bênh viên $E$ - Bô Y tế

Chiu trách nhiệm chính: Nguyễn Trung Hà Tâm

Email: hatamytb@gmail.com

Ngày nhân bài: 10.5.2021

Ngày phản biện khoa học: 2.7.2021

Ngày duyệt bài: 12.7.2021
}

\section{Nguyễn Trung Hà Tâm 1 , Đặng Hồng $\mathrm{Hoa}^{2}$ I. ĐĂT VẤN ĐỀ}

Đau côt sống thắt lưng (CSTL) là một triệu chứng phổ biến của rối loạn cơ xương, bao gồm các triệu chứng đau, căng cơ, cứng khớp hoặc đau vùng được giới hạn bởi dưới mép sườn và trên nếp cơ mông, có thể có hoặc không kèm đau thần kinh tọa [5]. Đau CSTL mạn tính là khi cơn đau tồn tại liên tục trong 12 tuần trở lên.

Bình thường, Vitamin D3 (25-OH) (Vitamin D3) huyết thanh có vai trò quan trọng trong quá trình chuyển hóa xương để duy trì hệ xương khớp chắc khỏe. Ngoài ra, Vitamin D3 còn tham gia vào quá trình điều hòa miễn dịch giúp bảo vệ cơ thể chống lại bệnh tật. Trong những năm gần đây, sự thiếu hụt Vitamin D3 trên bệnh nhân đau CSTL mạn tính rất phổ biến [8], [9]. Nghiên cứu của Gokcek E. và cộng sự chỉ ra tỷ lê người bênh đau CSTL thiếu hụt Vitamin D3 chiếm 85,7\% [6]. Tại Viêt Nam đã có một số nghiên cứu về Vitamin D3 trên bệnh nhân mẳc các bệnh về cơ xương khớp như loãng xương, viêm cột sống dính khớp, gout, lupus ban đỏ hệ thống... Hiện chưa có nghiên cứu nào về tình trạng thiếu Vitamin D3 ở bệnh nhân đau CSTL mạn tính. Vì vậy, chúng tôi thực hiện đề tài này với mục tiêu: Xác định nồng độ Vitamin $D 3$ và khảo sát tình trang thiêu Vitamin D3 (25-OH) huyêt thanh ở những người bệnh đau cột sống thắt lưng mạn tính.

\section{II. ĐỐI TƯỢNG VÀ PHƯƠNG PHÁP NGHIÊN CỨU \\ 2.1. Đối tượng nghiên cứu}

Tiêu chuẩn lựa chọn. Đối tượng nghiên cứu (ĐTNC) là những người bệnh được chẩn đoán đau CSTL mạn tính không do viêm được điều trị tai Khoa cơ xương khớp Bênh viên $\mathrm{E}$ từ tháng 03/2021 đến tháng 04/2021 và đồng ý tham gia nghiên cứu.

Tiêu chuẩn loại trừ. Những người bị đau cột sống thắt lưng cấp và mạn tính do các bệnh lý khớp viêm, Hội chứng rối loạn hấp thu, bệnh Crohn, phẫu thuật nối tắc dạ dày ruột. Tiền sử hoặc hiện đang sử dụng thuốc ảnh hưởng đến chuyển hóa Vitamin D3: Rifampicin, Rocaltrol, Carbamazepine, Cimetidine...Người mắc bệnh có liên quan đến chuyển hóa Vitamin D3: Suy thận mạn, suy gan mạn, suy tuyến cận giáp, đái tháo đường, hội chứng cushing.

\subsection{Phương pháp nghiên cứu}

Thiết kế nghiên cứu: Nghiên cứu mô tả cắt 
ngang, phân tích nội nhóm.

Cỡ mẫu nghiên cứu:

Áp dụng công thức cỡ mẫu ước tính cho một bệnh mạn tính trong bệnh viện [1]

$$
n=Z_{(1-\alpha / 2)}^{2} \frac{(1-p) p}{d^{2}}
$$

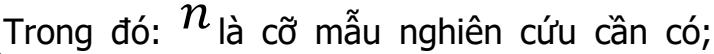
$Z_{(1-\alpha / 2)}^{2}=1,96(\mathrm{a}=5 \%) ; p=0,92_{\text {theo }}$ ước tính về tỷ lệ thiếu vitamin $D$ ở bệnh nhân CXK tại khoa nội Cơ xương khớp, Bệnh viện Chợ Rẫy, năm 2011 [2]; $d=0,06$ là độ chính xác tương đối so với $\boldsymbol{p}$.

Số mẫu (n) tính được là 79. Thực tế có 82 người bệnh đủ tiêu chuẩn tham gia nghiên cứu.

Phương pháp thu thập số liệu. Thông tin cá nhân của người bệnh được thu thập dựa trên bộ câu hỏi có sẵn. Hỏi bệnh và khám lâm sàng. Xét nghiệm nồng độ Vitamin D3 trong mẫu huyết thanh được thực hiện tại khoa Hóa sinh, Bệnh viện $\mathrm{E}$, trên máy phân tích miễn dịch Coban $\mathrm{E}$ 6000 của hãng Roche. Giá trị Vitamin D3 25(OH) huyết thanh được chia 3 mức độ: thiếu nặng: $\leq$ $20 \mathrm{ng} / \mathrm{ml}$, thiếu vừa: $21-29 \mathrm{ng} / \mathrm{ml}$ và bình thường: $\geq 30 \mathrm{ng} / \mathrm{ml}$ [7].

Phân tích số liêu. Các số liêu sau khi thu thập được kiểm tra, làm sạch, mã hoá và nhập bẳng phần mềm Epidata 3.1 sau đó xử lý thống kê bằng phần mềm Stata 12.0.

Đạo đức nghiên cứu. Đề tài đã được Hội đồng đạo đức trường Đại học Y Hà Nội, Bệnh viện E Hà Nội thông qua. Thông tin thu thập từ nghiên cứu được mã hóa, mọi thông tin định danh được giữ kín. Các kết quả được phân tích tổng hợp, không công bố thông tin cá nhân và chỉ được phân tích phục vụ đúng cho mục tiêu nghiên cứu.

\section{KẾT QUẢ NGHIÊN CỨU}

Trong số 82 ĐTNC bị đau CSTL mạn tính, tỷ lệ nữ chiếm $74,4 \%$, nữ/nam là $2,9 / 1$, tuổi trung bình là $67,6 \pm 12,7$ năm, hầu hết các ĐTNC trên 60 tuổi $(72,0 \%)$, tỷ lệ ĐTNC ở nhóm lao động nhẹ là $57,3 \%$ và lao động từ trung bình đến nặng chiếm $41,5 \%$. Các bệnh lý kèm theo phố biến bao gồm: THA $(45,1 \%)$, đái tháo đường $(18,3 \%)$ và Gút $(12,2 \%)$.

3.1. Nông độ Vitamin $D 3$ và tình trang thiếu Vitamin D3 ở người bệnh đau CSTL man tính

Bảng 1. Nồng độ Vitamin D3 huyêt thanh của các ĐTNC

\begin{tabular}{|c|c|c|c|c|}
\begin{tabular}{|c|c|c|} 
Mức độ thiếu \\
Vitamin D3 \\
huyết thanh
\end{tabular} & $\mathbf{n}$ & $\mathbf{\%}$ & $\mathbf{X} \pm \mathbf{S D}$ & $\begin{array}{c}\text { Min - } \\
\text { Max }\end{array}$ \\
\cline { 1 - 3 } Thiếu nặng & 44 & 53,7 & $19,8 \pm 7,7$ & $3-$ \\
\cline { 1 - 3 } Thiếu vữa & 32 & 39,0 & $\begin{array}{r}1,8 \\
\text { ng/ml }\end{array}$ & 46,9 \\
\hline Bình thường & 6 & 7,3 & \\
\hline
\end{tabular}

Trong 82 bênnh nhân nghiên cứu tỷ lệ thiếu hụt vitamin D3 chiếm tới 92,7\%. Nồng độ vitamin D3 huyết thanh trung bình là $19,8 \pm 7,7 \mathrm{ng} / \mathrm{ml}$.

3.2. Mối liên quan giữa nồng độ vitamin D3 với một số yếu tố ở người bệnh đau CSTL mạn tính

Bảng 2. Mức độ thiêu Vitamin D3 và đặc điểm nhân khẩu học

\begin{tabular}{|c|c|c|c|c|c|c|c|}
\hline \multirow{3}{*}{ Đặc điểm } & \multicolumn{6}{|c|}{ Mức độ thiếu Vitamin D3 huyết thanh $(n=82)$} & \multirow{3}{*}{ p } \\
\hline & \multicolumn{2}{|c|}{ Thiếu nặng } & \multicolumn{2}{|c|}{ Thiếu vừa } & \multicolumn{2}{|c|}{ Bình thường } & \\
\hline & $\mathbf{n}$ & $\%$ & $\mathbf{n}$ & $\%$ & $\mathbf{n}$ & $\%$ & \\
\hline Tuối & \multicolumn{2}{|c|}{$66,6 \pm 13,4$} & \multicolumn{2}{|c|}{$69,4 \pm 12,1$} & \multicolumn{2}{|c|}{$67,8 \pm 11,5$} & 0,803 \\
\hline Giới tính: Nam & 7 & 15,9 & 10 & 31,2 & 4 & 66,7 & \\
\hline Nữ & 37 & 84,1 & 22 & 68,8 & 3 & 33,3 & 0,035 \\
\hline
\end{tabular}

*p tính theo của Anova test, Fisher test

Sự khác biệt về tỷ lệ thiếu hụt Vitamin D3 giữa hai giới có ý nghĩa thống kê với p = 0,035 < 0,05.

Bảng 3. Mức độ thiếu Vitamin D3 và tình trạng hút thuốc lá ở nam giới

\begin{tabular}{|c|c|c|c|c|c|c|c|}
\hline \multirow{3}{*}{ Hút thuốc lá } & \multicolumn{6}{|c|}{ Mức độ thiếu Vitamin D3 huyết thanh $(n=21)$} & \multirow{3}{*}{$\mathbf{p}$} \\
\hline & \multicolumn{2}{|c|}{ Thiếu nặng } & \multicolumn{2}{|c|}{ Thiếu vừa } & \multicolumn{2}{|c|}{ Bình thường } & \\
\hline & $\mathbf{n}$ & $\%$ & $\mathbf{n}$ & $\%$ & $\mathbf{n}$ & $\%$ & \\
\hline Có & 6 & 85,7 & 6 & 60,0 & 0 & 0,0 & \\
\hline Không & 1 & 14,3 & 4 & 40,0 & 4 & 100 & 3 \\
\hline
\end{tabular}

*p tính theo của Fisher test

Nam giới hút thuốc lá có tỷ lệ thiếu hụt Vitamin D3 cao hơn nhóm không hút thuốc lá, sự khác biệt có ý nghĩa thống kê $(p=0,043<0,05)$.

Bảng 4. Mức độ thiếu Vitamin D3 và tình trạng uống rượu ở nam giới

\section{Mức độ thiếu Vitamin D3 huyết thanh $(n=21)$}

Uống rượu

\begin{tabular}{|l|l|l|l|}
\multicolumn{2}{|c|}{ Thiếu năng } & \multicolumn{2}{|c}{ Thiếu vừa } \\
\hline n & $\%$ & n & $\%$
\end{tabular}

$\%$

Bìn 
VIETNAM MEDICAL JOURNAL N01 - AUGUST - 2021

\begin{tabular}{|c|c|c|c|c|c|c|c|}
\hline Có & 6 & 85,7 & 8 & 80,0 & 1 & 25,0 & \multirow{2}{*}{0,022} \\
\hline Không & 1 & 14,3 & 2 & 20,0 & 3 & 75,0 & \\
\hline \multicolumn{8}{|c|}{$\begin{array}{l}\text { *p tính theo của Fisher test } \\
\text { Tỷ lệ thiếu hưt Vitamin } \mathrm{D} 3 \text { ở nhóm nam giới có uống rượu cao hơn so với nhóm không uống rượu } \\
\text { sự khác biệt có ý nghĩa thống kê }(p=0,022<0,05) \text {. } \\
\text { Bảng } \mathbf{5} \text {. Mức độ thiếu Vitamin D3 và triệu chứng cơ năng }\end{array}$} \\
\hline \multirow{3}{*}{$\begin{array}{l}\text { Triệu chứng } \\
\text { cơ năng }\end{array}$} & \multicolumn{6}{|c|}{ Mức độ thiếu Vitamin D3 huyết thanh $(n=82)$} & \multirow{3}{*}{$\mathbf{p}$} \\
\hline & \multicolumn{2}{|c|}{ Thiếu nặng } & \multicolumn{2}{|c|}{ Thiếu vừa } & \multicolumn{2}{|c|}{ Bình thường } & \\
\hline & $\mathrm{n}$ & $\%$ & $\mathrm{n}$ & $\%$ & $\mathrm{n}$ & $\%$ & \\
\hline \multicolumn{8}{|c|}{ Triệu chứng yếu cơ } \\
\hline Có & 7 & 15,9 & 0 & 0,0 & 1 & 16,7 & \multirow{2}{*}{0,034} \\
\hline Không & 37 & 84,1 & 32 & 100 & 5 & 83,3 & \\
\hline \multicolumn{8}{|c|}{ Triệu chứng dị cảm } \\
\hline Có & 19 & 43,2 & 9 & 28,1 & 3 & 50,0 & \multirow{2}{*}{0,356} \\
\hline Không & 25 & 56,8 & 23 & 71,9 & 3 & 50,5 & \\
\hline
\end{tabular}

*p tính theo của Fisher test

Có sự khác biệt có ý nghĩa thống kê về tỷ lệ thiếu hụt Vitamin D3 liên quan đến triệu chứng yếu co $(p=0,034<0,05)$.

Bảng 6. Mức độ thiêu vitamin D3 và các chỉ sốlượng giá

\begin{tabular}{|c|c|c|c|c|}
\hline \multirow{2}{*}{ Chi số } & \multicolumn{3}{|c|}{ Mức độ thiếu Vitamin D3 huyết thanh (n = 82) } & \multirow{2}{*}{ p } \\
\cline { 2 - 5 } & Thiếu nặng & Thiếu vừa & Bình thường & 0,597 \\
\hline Thang điếm VAS & $3,3 \pm 0,6$ & $3,6 \pm 0,7$ & $3,1 \pm 0,5$ & 0,5 \\
\hline Chì số Oswestry & $19,6 \pm 7,0$ & $17,4 \pm 8,6$ & $16,2 \pm 7,9$ & $\mathbf{0 , 0 0 1}$ \\
\hline
\end{tabular}

*p tính theo của Anova test

Chỉ số Oswestry trung bình ở nhóm ĐTNC bị thiếu hụt Vitamin D3 cao hơn có ý nghĩa thống kê so với nhóm ĐTNC có Vitamin D3 trong giới hạ bình thường với $\mathrm{p}<0,05$.

Bảng 7. Mức độ thiêu vitamin D3 và một số chỉ số cận lâm sàng

\begin{tabular}{|c|c|c|c|c|}
\hline \multirow{2}{*}{ Chỉ số } & \multicolumn{2}{|c|}{ Mức độ thiếu Vitamin D3 huyết thanh (n = 82) } & \multirow{2}{*}{ p } \\
\cline { 2 - 5 } & Thiếu năng & Thiếu vứa & Bình thường & $\mathbf{0 , 0 9}$ \\
\hline Glucose (mmol/I) & $\mathbf{5 , 6} \pm \mathbf{1 , 7}$ & $\mathbf{6 , 4} \pm \mathbf{2 , 2}$ & $\mathbf{6 , 0} \pm \mathbf{1 , 0}$ & $\mathbf{0}, \mathbf{0}$ \\
\hline Calci (mmol/I) & $2,2 \pm 0,1$ & $2,2 \pm 0,1$ & $2,3 \pm 0,1$ & 0,600 \\
\hline Phospho máu (mmol/I) & $1,1 \pm 0,2$ & $1,1 \pm 0,2$ & $1,1 \pm 0,1$ & 0,370 \\
\hline ALP (UI/L) & $79,3 \pm 31,0$ & $93,1 \pm 60,6$ & $64,1 \pm 11,9$ & $\mathbf{0 , 0 0 0}$ \\
\hline
\end{tabular}

*p tính theo của Anova test

Nông độ ALP máu của nhóm ĐTNC bị thiếu hụt Vitamin D3 cao hơn có ý nghĩa thống kê so với nhóm ĐTNC có Vitamin D3 trong giới hạn bình thường với $\mathrm{p}<0,05$.

Bảng 8. Mức độ thiếu Vitamin D3 và mật độ xương cột sống ở nữ giới

\begin{tabular}{|c|c|c|c|c|c|c|c|}
\hline \multirow{3}{*}{$\begin{array}{c}\text { Mật độ xương } \\
\text { cột sống }\end{array}$} & \multicolumn{6}{|c|}{ Mức đô thiếu Vitamin D3 huyết thanh $(n=61)$} & \multirow{3}{*}{$\mathbf{p}$} \\
\hline & \multicolumn{2}{|c|}{ Thiếu nặng } & \multicolumn{2}{|c|}{ Thiếu vừa } & \multicolumn{2}{|c|}{ Bình thường } & \\
\hline & $\mathrm{n}$ & $\%$ & $\mathrm{n}$ & $\%$ & $\mathrm{n}$ & $\%$ & \\
\hline Bình thường & 6 & 17,6 & 2 & 9,1 & 3 & 60,0 & \multirow{3}{*}{0,013} \\
\hline Giảm & 6 & 17,6 & 9 & 40,9 & 2 & 40,0 & \\
\hline Loãng xương & 22 & 64,7 & 11 & 50,0 & 0 & 0,0 & \\
\hline
\end{tabular}

*p tính theo của Fisher test

Tỷ lệ giảm mất độ xương và loãng xương cột sống ở những phụ nữ có thiếu hụt Vitamin D3 cao hơn hẳn so với nhóm có Vitamin D3 bình thường, sự khác biệt có ý nghĩa thống kê ( $p=0,013<0,05)$.

\section{BÀN LUẬN}

Đối tượng tham gia nghiên cứu có đặc điểm chung khá tương đồng so với nghiên cứu về nông độ Vitamin D3 trên bệnh nhân bệnh lý thắt lưng, tỷ lệ nữ giới chiếm trên 50\% [4], [8]. Tuy nhiên, độ tuổi trung bình tại nghiên cứu này cao hơn so với đa số các nghiên cứu khác cùng chủ đề [4], [6], [8].
Nồng đồ Vitamin D3 huyết thanh trung bình ở bệnh nhân đau CSTL mạn tính trong nghiên cứu là $19,8 \pm 7,7 \mathrm{ng} / \mathrm{ml}$ và nhóm đối tượng thiếu nặng Vitamin D3 có tỷ lệ 53,7\% (bảng 1), kết quả này cao hơn so với nghiên cứu tại miên Bắc nước ta trên nhóm đối tượng người bình thường với tỷ lệ thiếu Vitamin D3 là 23,8\%. Ngoài ra, tỷ lệ này cao hơn so với hâu hết các nghiên cứu 
được tìm thấy trên cùng nhóm đối tượng bệnh nhẩn cơ xương khớp mạn tính. Cụ thể, nghiên cứu của Calik Y. và cộng sự cho thây $22,8 \%$ bệnh nhân thiếu Vitamin D3 hay nghiên cứu của Turner và cộng sự cho thấy tỷ lệ thiếu Vitamin D3 là $26 \%[4],[8]$. Điều này có thể dễ dàng lý giải bởi đối tượng trong nghiên cứu của chúng tôi có độ tuổi trung bình cao hơn so với các nghiên cứu khác và sự khác biệt giữa đặc điểm địa lý, văn hóa và lối sống giữa các nghiên cứu, những yếu tố này gây ra sự khác biệt giữa tỷ lế thiếu Vitamin D3 ở các nghiên cứu [4]. Bên cạnh đó, có một số nghiên cứu khác cho thấy tỷ lệ thiếu nặng Vitamin D3 cao hơn so với nghiên cứu của chúng tôi, cụ thể nghiên cứu của Gokcek $\mathrm{E}$. cho tỷ lệ là $85,7 \%$ bệnh nhân thiếu Vitamin D3 [6]. Tuy nhiên, điêuu này có thể được giải thích khi các nghiên cứu trên tiến hành trển nhóm đối tượng đau CSTL mạn tính có kèm theo các tiêu chuẩn khác so với nghiên cứu của chúng tôi, như trong thời gian nghiên cứu có triệu chứng đau hoặc thời gian có biểu hiện đau thắt lưng kéo dài trên 6 tháng [6]. Mặc dù, có sự khác nhau giữa tỷ lệ thiếu Vitamin D3 tại các nghiên cứu nhưng hầu hết các nghiên cứu đều nhấn mạnh thực trạng thiếu Vitamin D3 ở bệnh nhân đau CSTL và cần có những biện pháp để giải quyết vấn đề này.

Nghiên cứu đánh giá mối liên quan giữa tình trạng thiếu Vitamin D3 huyết thanh cho thấy giới tính, sự thay đổi mức độ hạn chế chức năng sinh hoạt được đánh giá bằng chỉ số Oswestry và nồng độ ALP có sự khác biệt giữa các nhóm đối tượng có mức độ thiếu Vitamin D3 khác nhau. Kết quả nghiên cứu của chúng tôi cho thấy tỷ lệ thiếu hụt Vitamin D3 ở phụ nữ cao hơn hẳn so với nam giới, sự khác biệt có ý nghĩa thống kê với $p<0,05$ (bảng 2). Kết quả này phù hợp với nhiều nghiên cứu đã công bố trước đây cho rằng tỷ lệ thiếu hụt Vitamin D3 ở nữ giới thường cao hơn so với nam giới [4], [8].

Kết quả nghiên cứu của chúng tôi cho thấy một số lối sống có hại với sức khỏe của bệnh nhân liên quan có ý nghĩa thống kê $(p<0,05)$ với tình trạng thiếu hụt Vitamin D3 (bảng 3,4 ). Các nghiên cứu gần đây đã gợi ý về mối liên quan giữa tình trạng thiếu hựt Vitamin D3 với một số lối sống có hại đối với sức khỏe như sự lạm dụng rượu bia, hút thuốc lá. Kết quả nghiên cứu cũnng cho thây có $7 / 8$ bệnh nhân yếu cơ bị thiếu nặng Vitamin D3 (bảng 5 ). Calik và cộng sự báo cáo mức độ hạn chế vận động ở nhóm đối tượng bị thiếu Vitamin D3 cao hơn so với nhóm đối tượng có nồng độ Vitamin D3 bình thường [4]. Nghiên cứu của Bischoff và cộng sự cho báo cáo với kết quả sức mạnh và chức năng cơ bắp ở bệnh nhân 60 tuổi trở lên bị thiếu Vitamin D3 thấp hơn so với bệnh nhân có mức Vitamin D3 bình thường [3]. Có thể giải thích, việc thiếu Vitamin D3 sẽ làm tăng độ nhạy cảm với cơn đau và giảm hoạt động chức năng thần kinh và cơ bắp, dẫn đến yếu cơ [9].

Chỉ số Oswestry thường được sử dụng trong các nghiên cứu để đánh giá sự thay đổi mức độ hạn chế sinh hoạt ở bệnh nhần bị đau cột sống thắt lưng. Trong nghiên cứu của chúng tôi (bảng 6) cho thấy chỉ số Oswestry cao nhất ở nhóm ĐTNC bị thiếu Vitamin D3 huyết thanh ở mức độ nặng và thấp nhất ở nhóm có nồng độ vitamin D3 trong giới hạn bình thường, sự khác biệt có ý nghĩa thống kê $(p<0,05)$. Điều này giải thích tại sao những đối tượng phải làm việc trong điều kiện thiếu ánh nắng mặt trời như trong văn phòng, trong các xưởng sản xuất công nghiệp khép kín thường có tỷ lệ đau cột sống thắt lưng cao và thời gian đau dai dẳng, kéo dài. Mặc dù có nhiều nghiên cứu đã công bố trước đây cho thấy có mối liên quan giữa mức độ thiếu Viamin D3 với chỉ số đánh giá mức độ đau VAS [4], [6], [8]. Trong nghiên cứu của chúng tôi, không tìm thấy sự khác biệt có ý nghĩa giữa chỉ số VAS với các mức độ thiểu Vitamin D3 (bảng 6), điều này có thể lý giải là do đối tượng nghiên của chúng tôi là đau thắt lưng mạn tính, vì vậy chỉ số lượng giá đau (VAS) có thể ít có ý nghĩa hơn so với chì số đánh giá chức năng vận động (Oswestry). Lodh và cộng sự đã nhấn mạnh sư khác biệt có ý nghĩa giữa nồng độ ALP ở các nhóm bệnh nhân có mức độ thiếu Vitamin D3 khác nhau [9], kết luận này cũng phù hợp với các kết quả chúng tôi thu được trong quá trình nghiên cứu (bảng 7). Một số đặc điểm cận lâm sàng khác như nồng độ calci toàn phần, đường, phospho máu trong nghiên cứu của chúng tôi chưa tìm thây mối liên quan với mức độ thiếu Vitamin D3 huyết thanh (bảng 7) điều này có thể là do cỡ mâuu nghiên cứu của chúng tôi chưa đủ lớn.

Khảo sát mối liên quan giữa mật độ xương ở cột sống thắt với tình trạng thiếu Vitamin D3 trong nghiên cứu của chúng tôi cho thấy tỷ lệ giảm mật độ xương và loãng xương cột sống ở những phụ nữ có thiếu hụt Vitamin D3 cao hơn hẳn so với nhóm có Vitamin D3 bình thường, sự khác biệt có ý nghĩa thống kê với $p<0,05$ (bảng 8). Kết quả này tương tự nghiên cứu của Nguyễn Thị Thanh Hương khi phân tích hồi quy tuyến tính nhiều lần cũng cho kết quả nồng độ Vitamin $D$ có mối liên quan đồng biến với mật độ xương ở phụ nữ $(p<0,001)$. 


\section{KẾT LUẬN}

Khảo sát 82 đối tượng nghiên cứu bị đau CSTL mạn tính, không phẩn biệt giố tính cho thây: Nồng độ Vitamin D3 huyết thanh trung bình là 19,8 \pm 7,7 ng/ml; trong đó tỷ lệ thiếu nặng chiếm $53,7 \%$ và thiếu vừa là $39,0 \%$. Một số yếu tố ảnh hưởng đến nồng độ Vitamin D3 huyết thanh có ý nghĩa $(p<0,05)$ bao gồm: giới tính, tình trạng hút thuốc lá, tình trạng uống rượu (ở nam giới), triệu chứng yếu cơ trền lâm sàng, mức độ hạn chế sinh hoạt (chỉ số Oswestry), chỉ số ALP, giảm mật độ xương cột sống ở phụ nữ. Những kết quả này cho thấy thực trạng thiếu vitamin D3 đặc biệt ở bệnh nhân đau thắt lưng mãn tính và những khuyến nghị về sự cần thiết phải sàng lọc tình trạng thiếu vitamin $D$ ở những người bệnh bị đau cột sống thắt lưng mạn tính để có kế hoạch điều trị phù hợp.

\section{TÀI LIÊU THAM KHẢO}

1. Đoàn Quốc Hưng (2018). Phương pháp nghiên cứu trong y sinh học (sách đào tạo sau đại học), Nhà Xuất bản Y học, Hà Nội.

2. Lê Anh Thư, Hưỳnh Vằn Khoa, Huỳnh Phan Phúc Linh và cộng sự. (2011). Đánh giá tình trạng vitamin $D$ của bệnh nhân nội trú tại khoa Nội Cở Xương Khớp, Bệnh viện Chợ Rẫy. Tạp chí Y học
TP Hồ Chí Minh, 15(4), 154-159.

3. Bischoff-Ferrari H.A., Dietrich T., Orav E.J., et al. (2004). Higher 25-hydroxyvitamin D concentrations are associated with better lower-extremity function in both active and inactive persons aged $>$ or $=60$ y. Am J Clin Nutr, 80(3), 752-758.

4. Çalık Y., Aygün Ü. (2017). Evaluation of vitamin D levels in patients with chronic low back-leg pain. Acta Orthop Traumatol Turc, 51(3), 243-247.

5. Chou R. (2011). Low Back Pain (Chronic). AFP, 84(4), 437-438.

6. Gokcek E., Kaydu A. (2018). Assessment of Relationship between Vitamin D Deficiency and Pain Severity in Patients with Low Back Pain: A Retrospective, Observational Study. Anesth Essays Res, 12(3), 680-684.

7. Holick M.F., Binkley N.C., Bischoff-Ferrari H.A., et al. (2012). Guidelines for Preventing and Treating Vitamin D Deficiency and Insufficiency Revisited. J Clin Endocrinol Metab, 97(4), 1153-1158.

8. Kanaujia V., Yadav R.K., Verma S., et al. (2021). Correlation between Vitamin D deficiency and nonspecific chronic low back pain: A retrospective observational study. J Family Med Prim Care, 10(2), 893-897.

9. Lodh M., Goswami B., Mahajan R.D., et al. (2015). Assessment of Vitamin D status In Patients of Chronic Low Back Pain of Unknown Etiology. Ind J Clin Biochem, 30(2), 174-179.

\title{
NGHIÊN CỨU BƯớC ĐÂU VỀ CAGPAI, OIPA, DUPA CỦA HELICOBACTER PYLORI Ở BÊ̂NH NHÂN UNG THƯ DẠ DÀY TẠI VIỆT NAM
}

\author{
Vũ Văn Khiên', Đoàn Vũ Nam², Nguyễn Quang Duật ${ }^{2}$, \\ Phạm Hồng Khánh ${ }^{2}$, Trần Thị Huyền Trang ${ }^{1}$
}

\section{TÓM TẮT}

Đặt vấn đê: Từ năm 1994, WHO đã xếp H.pylori nằm trong nhóm I gây UTDD. Tuy nhiên, khả năng gây bệnh của $\mathrm{H}$. pylori phụ thuộc vào yếu tố độc lực của nó. Đề tài nghiên cứu về tỷ lệ cagPAI, oipA, dupA ở bệnh nhân UTDD tại Việt Nam. Đối tướng và phương pháp: 31 bệnh nhẩn UTDD được chẩn đoán xác định trên nội soi và mô bệnh học. CagPAI, oipA, dupA được thực hiện bằng kỹ thuật PCR. Kêt quả: Bệnh nhẩn $\geqq 60$ tuổi chiếm: 64,5\%. Nam nhiều hơn nữ: 2,1 . Các triêu chứng lâm sàng hay gặp: Chán ăn $(90,3 \%)$, khó tiêu $(90,3 \%)$, đau thương vị $(83,9 \%)$. Mô bệnh học: Ung thư dạ dày thể ruột chiếm tỷ lệ cao nhất: $64,5 \%$. Tỷ lệ cagPAI, oipA, dupA dương tính ở bệnh nhân UTDD tương ứng là: $90,3 \%, 32,3 \%$,

\footnotetext{
${ }^{1}$ Bệnh viện TWQĐ 108

Bệnh viện quân y 103-Học viện Quân Y

Chịu trách nhiệm chính: Vũ Vắn Khiên

Email: vuvankhien108@yahoo.com.vn

Ngày nhận bài: 12.5.2021

Ngày phản biên khoa học: 5.7.2021

Ngày duyệt bài: 15.7.2021
}

$51,6 \%$. Kết luân: Gen cagPAI của H. pylori là yếu tố nguy cơ cao gẩy UTDD tại Việt Nam. Cần nghiên cứu trên số lượng nhiều hơn

Tư khóa: Helicobacter pylori, ung thư dạ dày, viêm dạ dày mạn

\section{SUMMARY \\ INITIAL STUDY ON CAGPAI, OIPA, DUPA \\ OF HELICOBACTER PYLORI IN GASTRIC CANCER PATIENTS IN VIETNAM}

Introduction: Since 1994, WHO has classified H.pylori in group I causing gastric cancer. However, the pathogenicity of $\mathrm{H}$. pylori is highly dependent on its virulence factor. Research topic on the rate of cagPAI, oipA, dupA in gastric cancer patients in Vietnam. Patients and mehods: 31 patients with gastric cancer were confirmed on endoscopy and histopathology. CagPAI, oipA, dupA were performed by PCR. Results: Patients $\geqq 60$ years old accounted for: $64.5 \%$. More men than women: 2.1. Common clinical symptoms: Anorexia (90.3\%), dyspepsia $(90.3 \%)$, epigastric pain $(83.9 \%)$. Histopathology: Itestinal type accounted for the highest percentage $(64.5 \%)$. CagPAI, oipA, dupA were positive in gastric 